\title{
Applied Research in
}

\section{Managerial \\ Communication: \\ The Critical Link between
Knowledge and Practice}

Applying the lessons of managerial communication studies can help managers become more influential and effective in their daily activities.

BY JUDI BROWNELL

W hy are some of your colleagues more successful than others? Why do some managers seem to make all the right decisions while others flounder? You might at first assume the successful ones are lucky, or can attribute their success to intelligence, personality, or even the environment in which they grew up. What might not be readily apparent is that successful practitioners have acquired specific knowledge that contributes to their high performance.

While requisite knowledge can be gained in a number of ways - experience, training, and education, for instancepowerful insights and reliable guidance for hospitality leaders come from applied research in hospitality management. Principles drawn from research constitute a reliable knowledge base that enables practitioners to gain competitive advantage. Findings from applied research in the field of mana-

\section{(c) 2003, CORNELL UNIVERSITY}

gerial communication, as I explain in this article, facilitate the application of principles from all management disciplines to drive high performance.

Managers' failure to heed research findings can be detrimental to an organization, especially when such managers operate under misconceptions that reduce their effectiveness on the job. For instance, a recent study pointed out seven costly mistakes that human-resources professionals frequently make because they lack familiarity with current research findings. ${ }^{1}$ Included in this list were the beliefs that conscientiousness is a better predictor of employee performance than intelligence, and that integrity tests are unreliable because employees are likely to lie on them.

${ }^{1}$ S. Rynes, K. Brown, and A. Colbert, "Seven Common Misconceptions about HR Practices: Research Findings vs. Practitioner Beliefs," Academy of Management Executive, Vol. 16, No. 3 (2002), pp. 92-103. 


\section{EXHIBIT 1}

Integrated model of managerial communication research

\section{Findings from Applied Research:}

\section{Produces principles and guidelines}
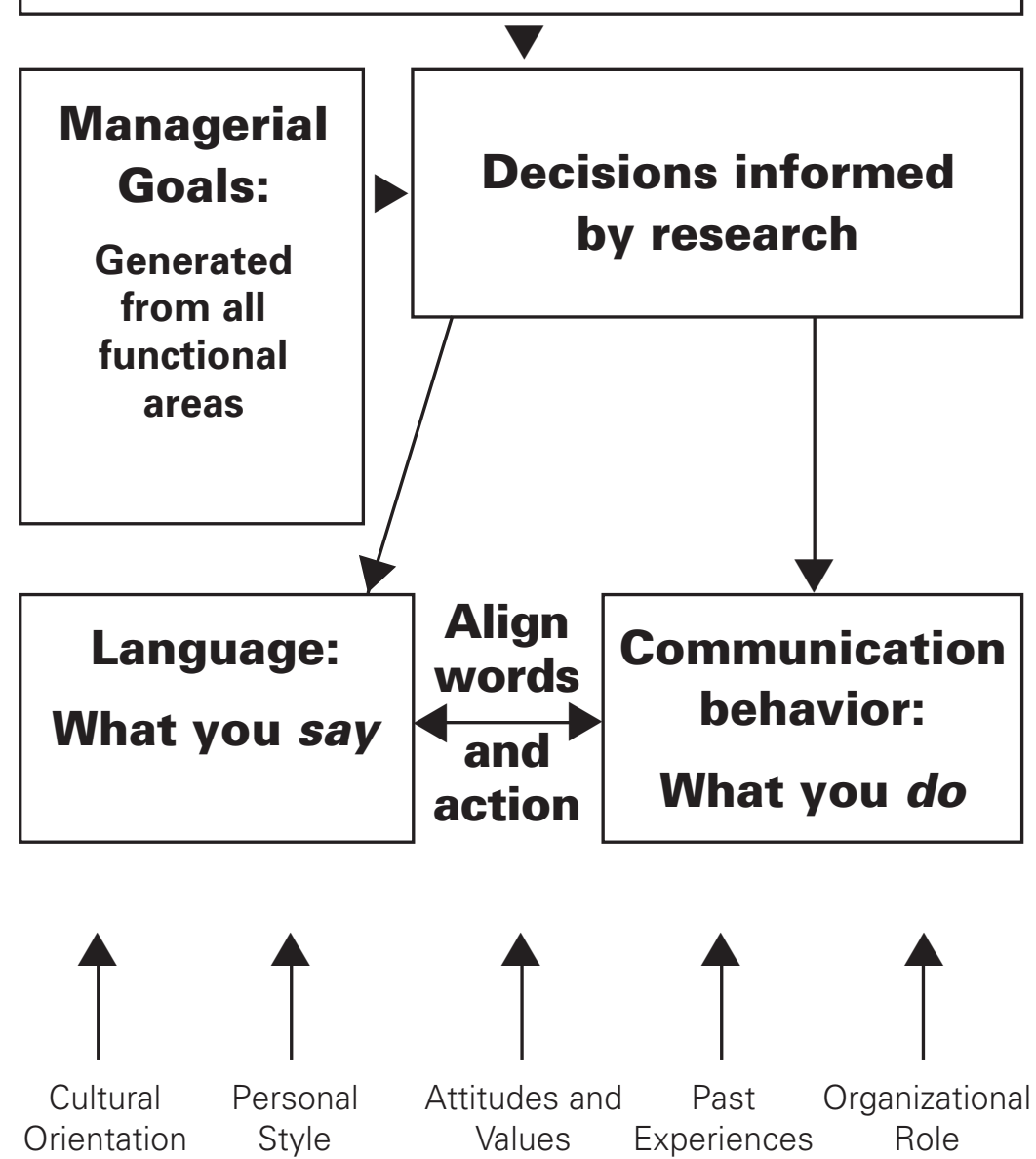

\section{E.Q. (emotional quotient): Sensitivity to} filters affecting managerial communication
Knowledge gained through applied research, however, is valuable only to the extent that managers can effectively implement the ideas and principles that they have acquired. Knowledge alone is insufficient to improve performance. For success, managers must be able to put knowledge to use. This critical task is accomplished through managers' language and behavior-that is, through their communication practices. All too frequently, talented managers with expertise in their field are unsuccessful because they lack the ability to communicate effectively. A marketing manager who has innovative ideas about how to capture more business travelers, for instance, will be passed over if she is unable to make her suggestions clear and compelling. Many strategic plans may never be implemented due to lack of communication savvy.

Applied managerial communication research informs practitioners' daily decisions about how best to get things done. In this article I demonstrate the critical role that findings from applied communication research play in providing a sound foundation on which to base decisions that direct language and behavior. Increased managerial communication effectiveness, in turn, enables practitioners to realize the benefits of functional area expertise as they work to improve individual and organizational performance.

I begin by discussing an integrative model that illustrates the critical relationship between applied research and managerial practice. Background information is presented to provide a context for understanding the origins and interdisciplinary nature of communication studies. Selected projects in the two major research areas of concern, language and behavior, are then reviewed to illustrate the usefulness of applied communication research in addressing practical issues and in achieving management goals. In each case, the value of managerial communication research for improving performance should be readily apparent.

Applicable Research: An Integrated Model

While the focus of this paper is on research in managerial communication, the model presented here provides a framework for understanding how the results of applied research in all fields 
can affect decision making and, consequently, increase effectiveness in the workplace. In this case, however, this integrative model (Exhibit 1) draws attention to the importance of applying knowledge generated from applied communication research to make better decisions about what to say and what to do to get desired results. In other words, effective communication is neither a function of trial and error nor is it a matter of doing what comes naturally. Effectiveness requires that you establish clear goals and then apply principles and insights to make wise choices about your language and behavior. My model also emphasizes that communication effectiveness directly affects managerial success, regardless of the scope or specific area of responsibility. Whether you are in accounting, finance, food and beverage, marketing, human resources, or other functional areas, putting your knowledge to use and achieving your goals requires the appropriate application of managerial communication principles.

Consistency. Language and behavior combine for maximum positive effect when they are consistent and aligned. Employees' perceptions of consistency between words and deeds - what Simons has termed behavioral integrity - is essential for establishing credibility and trust. ${ }^{2}$ Regardless of how skilled a communicator you might be, the ability to walk the talk is a critical success factor. While for convenience and clarity this discussion addresses language and behavior separately, it is essential that what you say and what you do present a consistent and unified impression. For instance, articulating a concern for employees' opinions but then never making yourself available, or talking about your belief in shared responsibility but refusing to allow employees to participate in decision making, will reduce your credibility and effectiveness.

In addition to applying principles developed from a solid knowledge base, successful managers also depend on emotional quotient (EQ), a dimension that captures the subjective, personal

\footnotetext{
${ }^{2}$ T. Simons, "Behavioral Integrity: The Perceived Alignment between Managers' Words and Deeds as a Research Focus," Organization Science, Vol. 13, No. 1 (2002), pp. 18-35.
}

evaluations used to make decisions at work. ${ }^{3}$ That is, skilled communicators are sensitive to the subjective and emotional aspects of a situation and respond accordingly. If you've looked at an employee and immediately realized that he's had a bad day or that cultural differences were responsible for someone's reluctance to speak up, then you've used your EQ. This element of personal judgment (i.e., social sensitivity) is always a factor in decision making and influences communication outcomes. Therefore, a box in the model draws attention to the filters that may color one's judgment and perceptions.

The full benefit of disciplinary research can be realized only if practitioners themselves become effective communicators by making informed choices about what they say and do. As an editor for Harvard Business Review recently lamented, "The wrong words, the wrong tone, the wrong expression - out of such everyday miscues come many of the world's problems, both small and large. In the world of business, the results of miscommunication are plain and painful: organizational strife, management paralysis, missed chances." 4

Regardless of your specific content area, findings from managerial communication research provide information that can be used readily to increase your effectiveness as you apply your expertise to workplace situations. Accountants who need to make an effective presentation to the executive committee, human-resources professionals who must motivate employees during downsizing, information-technology managers who are responsible for the smooth introduction of new computer systems, and food and beverage managers who want to ensure quality customer service are all more likely to accomplish their goals when they consider the results of managerial communication research.

\footnotetext{
${ }^{3}$ See: R.E. Boyatzis, E.C. Stubbs, and S.N. Taylor, "Learning Cognitive and Emotional Intelligence Competencies through Graduate Management Education," Academy of Management Learning and Education, Vol. 1, No. 2 (2002), pp. 150-162; and D. Goleman, R.E. Boyatzis, and A. McKee, Primal Leadership: Realizing the Power of Emotional Intelligence (Boston: Harvard Business School Press, 2002).

${ }^{4}$ S. Wetlaufer, "Can We Talk?," Harvard Business Review, Vol. 80, No. 3 (2001), p. 12.
} 


\section{EXHIBIT 2}

\section{Definition of Managerial Communication}

1 Managerial communication is an applied, interdisciplinary field focusing on language and behavior within an organizational context.

2 Managerial communication focuses on the individual manager as its unit of analysis.

3 Managerial communication research focuses on communication across various contexts-interpersonal, group, organizational and, in some instances, mediated.

4 Managerial communication includes all relevant forms and channels of communication that managers may select in accomplishing their purposes, including written, oral, nonverbal, and mediated.

\section{Managerial Communication \\ Research: Background}

For the purpose of this discussion, I distinguish managerial communication from other similar fields, such as organizational or business communication, by its level of analysis and by its focus of concern (Exhibit 2).

The discipline of communication can be studied as an art that emerges from the humanitiesbased study of rhetoric or as a social science with foundations in such fields as psychology, sociology, and anthropology. This difference in theoretical background has implications for the types of questions researchers ask and the methods they use to study their subjects.

Humanistic approaches. Scholarly communities find comfort in categorizing all things, including research methods. Theory and criticism in the humanities (typically the study of language) can be characterized as using primarily critical or analytical methods to gain insight into particular cases. Researchers might examine closely one particular document or a series of meetings to uncover principles that then can be applied to other similar situations. Common methods include discourse analysis (of both oral and written communication), narrative, oral history, ethnography, and participant observation. Such research generates theories that then can guide decision making and subsequently influence the way managers communicate and implement their ideas in the workplace.

Social Science approaches. Research in the social sciences (typically, the study of human be- havior), by contrast, usually tests hypotheses and develops generalizations based on quantitative methods. Social-science researchers may send out a survey to test hypotheses regarding trust in the purchaser-vendor partnership, for instance. Conclusions would be reached from analyzing the responses of a substantial number of participants. Depending on the nature of the questions addressed, methods might also include focus groups, interviews, and, somewhat less frequently, experimental designs.

In some instances social scientists also apply interpretive approaches to the study of human communication. They may observe interactions and then construct an interpretation that makes sense of the experience.

While such distinctions between humanities and social sciences can be useful, the best managerial communication research seeks to combine methods from both traditions and bring them to bear on timely and relevant hospitality-management concerns. Managerial communication research supplies the principles and insights that help practitioners to apply knowledge derived from all other disciplines as they seek to increase their effectiveness.

\section{Effective Use of Language: What You Say Counts}

Hospitality research spans a broad array of topics, from marketing and finance to property design and information systems. The application of research findings to improve management practice requires that practitioners communicate new directions, new methods, or new ideas with clarity and impact. Success depends on the skilled use of language. The relationship between language and thought has intrigued researchers for decades. Do the words we use shape and constrain our thoughts? Can we think at all without language to express our ideas? A major challenge for researchers has been to explain how language works - that is, why particular words in a particular sequence elicit a particular response from another person. Managerial communication researchers today explore the use and effects of symbols in daily organizational life. Unless you use language effectively, the knowledge you acquire cannot be put to use in accomplishing your goals. 


\section{Language and Diversity}

Given increasing specialization and growing organizational diversity, listeners do not always share a speaker's language or cultural background. For example, new insights into marketing cannot really translate into improved practice without considering the context in which the target audience operates. The problem can be amusing, such as when General Motors discovered that Nova meant "no go" in Spanish; when the Chinese interpreted the slogan "Pepsi Comes Alive" as "Pepsi brings your ancestors back from the grave"; or (as the story is told) when the Scandinavian manufacturer Electrolux used "Nothing sucks like an Electrolux" in its American vacuumcleaner ad campaign. ${ }^{5}$

The usefulness of applied research is also threatened when technical terms and jargon are used as though everyone had a similar background. When subject matter is technical, abstract, or complex, translating research into practice becomes increasingly difficult as the "terminology of finance, accounting, information technology, and other business fields befuddle readers who lack the specific technical background and vocabulary" of the communicator. ${ }^{6}$ In her rhetorical analysis, Jameson explores how effective writers put technical content into forms that are accessible to multiple readers, each of whom may approach his or her task from a different perspective. Her findings provide guidelines for others who find themselves confronting similar challenges. In part, journals like Cornell Quarterly address this issue by charging authors with making the practical application of their research findings clear. ${ }^{7}$

Accomplishing your goals through communication becomes particularly complicated when documents are designed for multiple audiences or addressed to one audience but intended for others as well. Huettman's study of hospitality consultants' reports over a two-year period, for instance, revealed that the writers' choices regard-

\footnotetext{
${ }^{5}$ See: www.essentialaction.org/tobacco/intro/funny.html.

${ }^{6}$ D. Jameson, "Telling the Investment Story: A Narrative Analysis of Shareholder Reports," Journal of Business Communication, Vol. 37, No. 1 (2000), p. 7.

${ }^{7}$ Michael C. Sturman, "Writing for Cornell Quarterly: What I Look for in a Submission," Cornell Hotel and Restaurant Administration Quarterly, Vol. 44, No. 1 (February 2003), p. 1.
}

ing language, structure, content, and other features were influenced by organizational politics and personal rewards, as well as by an assessment of the client's specific needs. ${ }^{8}$ Obviously, identifying and minimizing confounding factors provides a better product for the client.

Have you ever heard the expression, "meanings aren't in words; they're in people"? Even a seemingly simple concept like "office party" might mean different things to those from different cultures or even to those with past experiences in different organizations. ${ }^{9}$ Your idea of an office party might be a modest celebration of your team's accomplishments, while your new assistant manager may have in mind a gourmet banquet with a live band.

Whether at the corporate or unit level, decision making is potentially flawed by managers' assumptions and misconceptions about the most effective channels, sources, and language to employ in accomplishing their goals. It is common for the employees in an entire department to be people for whom English is a second language. In such contexts, managers must engage in deliberate communication planning to ensure that their intended meanings are accurately understood. ${ }^{10}$ The need for careful communication planning was highlighted in a study conducted at a luxury hotel, where surveys, focus groups, participant observation, and structured interviews were used to explore how service employees came to understand the meaning of "quality service" at their property. ${ }^{11}$ The main research question asked, "How do employees develop their understanding of what an appropriate response might be to a particular service situation?"

\footnotetext{
${ }^{8}$ E. Huettman, "Writing for Multiple Audiences: An Examination of Audience Concerns in a Hospitality Consulting Firm," Journal of Business Communication, Vol. 33, No. 3 (1996), pp. 257-272.

${ }^{9}$ M. Gallivan, "Meaning to Change: How Diverse Stakeholders Interpret Organizational Communication about Change Initiatives," IEEE Transactions on Professional Communication, Vol. 44, No. 4 (2001), pp. 243-266.

${ }^{10}$ A. Fox, "Mission Possible: Southern Hospitality Assimilates Hispanic Workers," HRMagazine, Vol. 45, No. 12 (2000), pp. 56-58.

${ }^{11} \mathrm{~J}$. Brownell and D. Jameson, "Getting Quality Out on the Street: A Case of Show and Tell." Cornell Hotel and Restaurant Administration Quarterly, Vol. 37, No. 1 (February 1996), pp. 28-33.
} 
The study found that the sources (such as newsletters, supervisors, peers, and guests) and contexts (such as meetings, training programs, and one-on-one discussions) that managers used to communicate service expectations were different from the sources and settings that the employees relied on for that information. Culture, gender, and other variables affect both employees' expectations and their information-seeking practices. The bottom line is that managers too often put considerable effort into communications that are missing their target audience completely. By developing increased sensitivity to language, you will be able to communicate wisely in an environment where failing to consider individual differences may result in unanticipated consequences. ${ }^{12}$

\section{The Language of Leadership}

Language is crucial in directing the course of human affairs. Public blunders in how thoughts are expressed, for instance, attest to the profound consequences of miscommunication. Recall the communication miscues of former vice president Dan Quayle, for instance, when he said "the future will be better tomorrow," or "I love California; I practically grew up in Phoenix," and "if we don't succeed, we run the risk of failure." His well-meant, but misdirected comments almost certainly damaged his credibility.

Vision. On the other hand, the skilled use of language instills confidence in listeners and creates images that motivate and inspire. For instance, the story is told of two masons, both working on the same project. When asked what they were doing, one says, "As you can see, I am cutting stones." The second, however, looks up from his work and replies, "I am building a great cathedral." Today's global hospitality leaders require the "language of leadership" as they create cathedrals, seeking images that will build cohesiveness and communicate their vision.

Once research findings are understood, achieving meaningful change requires both communication skills and leadership ability. Thus, there is

\footnotetext{
${ }^{12}$ E.L. Kirby and L.M. Harter, "Speaking the Language of the Bottom Line: The Metaphor of Managing Diversity," Journal of Business Communication, Vol. 40, No. 1 (2003), pp. 28-49.
}

also a growing emphasis on what has been termed "executive values." ${ }^{3}$ Executive values are principles that are developed, owned, and driven by the senior manager and his or her leadership team. To create a vision and inspire employees, leaders must avoid confusion, be consistent in their messages, and gain credibility with internal and external stakeholders. ${ }^{14}$ Cornell's Hotel School, for example, has framed a portion of its vision as addressing "four Rs"-namely, rigor, relationships, relevance, and reach. ${ }^{15}$ The message is effective with multiple stakeholders because its language is simple, clear, and consistent.

Studying leaders' language provides insights into their thoughts and actions. ${ }^{16}$ Strong leaders have a point of view that they clearly articulate in a way that motivates employees to action and mobilizes resources. Through language, executives describe a highly desirable and compelling world view. Success in translating applied research to actual practice thus depends on the leader's ability to articulate central messages in a vivid and memorable manner. ${ }^{17}$ Let's look at an example of how this might be accomplished.

Suppose that you have recently been to an executive-education seminar and that you have acquired new ideas and methods that you think can help improve your business. You might want to bring up such new insights at a meeting of

\footnotetext{
${ }^{13}$ S. French, "CEO Values Replace Corporate Values," Canadian HR Reporter, Vol. 15, No. 7 (2002), pp. 5-8.

${ }^{14}$ See: C.K. Barnett and N. Tichy, "How New Leaders Learn to Take Charge," Organizational Dynamics, Vol. 29, No. 1 (2000), pp. 16-32; P. Parker, "I Have a Dream: Communicating a Vision Helps Managers become Leaders," Pharmaceutical Executive, Vol. 21, No. 7 (2001), pp. 28-30; and C. Hardy, "Researching Organizational Discourse," International Studies of Management and Organization, Vol. 31, No. 3 (2001), pp. 25-47.

15 David W. Butler, "Looking Ahead," Cornell Hotel and Restaurant Administration Quarterly, Vol. 41, No. 4 (August 2000), inside front cover.

${ }^{16}$ I. Cunningham, "The Impact of Leaders: Who They Are and What They Do," Leadership and Organization Development Journal, Vol. 13, No. 2 (1992), pp. 7-15.

17 See: L. Heracleous and M. Barrett, "Organizational Change as Discourse: Communicative Actions and Deep Structures in the Context of Information-technology Implementation," Academy of Management Journal, Vol. 44, No. 4 (2001), pp. 755-778; and C. Copinath and T. Becker, "Communication, Procedural Justice and Employee Attitudes: Relationships under Conditions of Divestiture," Journal of Management, Vol. 26, No. 1 (2000), pp. 63-83.
} 
your top managers. Think about how information has typically been communicated in such meetings in the past. Most likely, after a few introductory remarks, facts and figures were presented on graphs while the speaker offered an outline of specific findings. This rational, factbased approach is typical of how managers traditionally have prepared their speaking assignments.

Now, however, think of yourself as a "meaning maker." ${ }^{18}$ Instead of focusing on the details, what would happen if your emphasis was on a vision that would inspire listeners and capture their imaginations? Perhaps you could say, "We are redefining the service experience so that when travelers think of luxury, they will imagine themselves transported to our tropical paradise." You might use metaphors to make your points vivid and compelling, as Kenneth Blanchard does, for example, when he asks, "Are you an eagle, or are you a duck? Do you soar high in the sky with lofty goals and visions, or do you run around in circles, quacking?" 19

Obviously, communications of that type have strong emotional elements. The effectiveness of emotional appeal in motivating and creating positive attitudes has been documented in a range of studies. ${ }^{20}$ The skilled use of language has helped organizations successfully handle any number of potential crises ${ }^{21}$ and should be critical for communicating a wide range of new practices and ideas. When perceptions of legitimacy are enhanced, credibility is increased and the way is cleared for crisis recovery. ${ }^{22}$

\footnotetext{
${ }^{18}$ J.A. Conger, "Inspiring Others: The Language of Leadership," The Executive, Vol. 5, No. 1 (1991), pp. 31-45.

${ }^{19} \mathrm{~K}$. Blanchard, The Heart of a Leader: Insights on the Art of Influence (Massapequa Park, NY: Honor Books, 1999).

${ }^{20}$ See: A. Mattila, "Do Emotional Appeals Work for Hotels? An Exploratory Study," Journal of Hospitality and Tourism Research, Vol. 25, No. 1 (2001), pp. 31-45; and S. Fox and Y. Amichai-Hamburger, "The Power of Emotional Appeals in Promoting Organizational-change Programs," Academy of Management Executive, Vol. 15, No. 4 (2001), pp. 84-95.

${ }^{21}$ M. Keleman, "Too Much or Too Little Ambiguity: The Language of Total Quality Management," Journal of Management Studies, Vol. 37, No. 4 (2000), pp. 483-498.

22 J.E. Massey, "Managing Organizational Legitimacy: Communication Strategies for Organizations in Crisis," Journal of Business Communication, Vol. 38, No. 2 (2001), pp. 153-183.
}

In their efforts to apply what they learn through communication research, managers would be wise to consider the symbolic function language plays and the strong impact it has on performance. Leaders of healthy organizational cultures are "symbolic managers," strategically applying language to create a compelling vision and to accomplish their highest priorities.

\section{Create Organizational Culture through Language}

In addition to using language to clarify and inspire, leaders also use language to understand, develop, and maintain cultures-in this case, organizational cultures. For instance, Palmer and Lundberg studied the metaphors and mental images employees held of their companies in the belief that metaphors both shape and reflect organizational reality. ${ }^{23}$ When employees were asked for examples of how they conceptualized their workplace, the images included "a mutinous pirate ship," "a big family," and "a sailboat in a calm breeze." 24 These researchers concluded that such metaphors had an influence on employees' job performance, and that by uncovering those metaphors managers would be in a better position to increase morale, reduce turnover, identify training needs, and uncover other critical information that could be used to improve the organizational practices.

Another method of shaping perceptions and creating and reinforcing organizational culture is through the stories you tell. Stories create, maintain, and perpetuate central organizational values. Through storytelling, your employees come to share a common emotional involvement and commitment; they develop similar attitudes because they are shown how to structure experiences in a meaningful, and common, manner.

An example of how a story conveys "the way we do things here" comes from a theme restaurant in a medium-size hotel. The food and beverage manager orients his new servers with an account of Katie and the button, and few of them

\footnotetext{
${ }^{23}$ I. Palmer and C. Lundberg, "Metaphors of Hospitality Organizations: An Exploratory Study," Cornell Hotel and Restaurant Administration Quarterly, Vol. 36, No. 3 (June 1995), pp. 80-90.

${ }^{24}$ Ibid., p. 85.
} 
ever forget his message. As the story goes, a couple had come into the restaurant for dinner and as the woman removed her coat a button came off. She quickly placed it in her pocket and then checked her coat with Katie, the hostess. Having noticed the incident, Katie found the appropriate materials and sewed the button back on the coat before the meal was over.

Taking a slightly different approach, Jameson studied a management team that collectively constructed stories to make sense of the past and to

\section{Communication practices are among the most potent tools for improving organizational effectiveness.}

problem solve. After extensive observation of the group's dynamics, she concluded that good story builders were "creative thinkers who used imagination and intuition to transform experience and knowledge into influence." 25

Research on Behavior: What You Do Counts

The editors of Harvard Business Review have identified what they referred to as "provocative concepts" that will be shaping effective management practice in the future. The first of these was what they called execution, the "hard and unglamorous work" of translating a strategy from language to action. ${ }^{26}$ Managerial communication research generates principles that help you in this critical task.

Communication is a high-leverage activity. That is, you receive large payoffs from small improvements in performance. Communication practices are, therefore, among the most potent tools for improving organizational effectiveness and implementing the ideas you have gained from applied hospitality research. The following are

\footnotetext{
${ }^{25}$ D. Jameson, "Narrative Discourse and Management Action," The Journal of Business Communication, Vol. 38, No. 4 (2001), p. 508.

26 "The 2001 HBR List, Breakthrough Ideas for Today's Business Agenda," Harvard Business Review, Vol. 79, No. 4 (2001), pp. 123.
}

examples of research projects in managerial communication that have generated principles and findings that contribute directly to increased individual and organizational performance.

\section{Communication Competencies and Career Development}

It would be useful to know what specific communication skills are correlated with managerial effectiveness, especially in conjunction with succession planning. Identifying future leaders who possess those characteristics required to meet the challenges of change and uncertainty is critical to corporate survival. Managerialcommunication scholars, primarily using survey research, engage in projects aimed to identify these key competencies. ${ }^{27}$

Listening, managing conflict, and leading teams are examples of skills that were perceived by general managers as being among the most essential requirements for those preparing for leadership at the unit level. In fact, in a study I recently conducted regarding the ingredients for success as a general manager, the ability to communicate effectively was ranked first of 23 broad leadership competencies. ${ }^{28}$ Respondents realized that, whether they were dealing with an employee grievance or trying to get approval for additional resources, their effectiveness depended on their communication ability.

Communication competence is often context specific-that is, behavior that produces desired results on a casino floor may not be effective in an island resort setting. The particular skills and personal traits required for success in specific industries such as health care, ${ }^{29}$ food service, ${ }^{30}$ and cruise ships recently

${ }^{27}$ See: J. Moody, B. Stewart, and C. Bolt-Lee, "Showing the Skilled Business Graduate: Expanding the Tool Kit," Journal of Business Communication, Vol. 65, No. 1 (2002), pp. 21-36; and D. Williams, "Communicate our Leadership Agenda," Executive Excellence, Vol. 18, No. 12 (2001), pp. $10-15$.

${ }^{28}$ Study results have not yet been published.

${ }^{29}$ J. Williams, F. DiMicco, and E. Shafer, "Attributes for Success in Health Care," Journal of Hospitality and Tourism Research, Vol. 24, No. 1 (2000), pp. 36-48.

${ }^{30}$ D. Reynolds, "Attributes for Success in Food Service," Journal of Hospitality and Tourism Research, Vol. 24, No. 1 (2000), pp. 92-103. 
have been studied. As managerial profiles are developed in each category, this research stream should prove particularly valuable in enhancing employee selection and development activities.

Personal style. Taking yet another approach to the question of critical personal competencies, a number of researchers have investigated the effects of an individual's style preferences on performance. One of the most well-known and reliable assessments used for studying personal style and the fit between an individual and a job is the Myers-Briggs Type Indicator (MBTI). ${ }^{31}$

The MBTI assesses an individual's preferences on four scales, including how they acquire information (by intuition or investigation), how they process information (thinking versus feeling), how they relate to people (finding renewal in personal interactions or from being alone), and their approach to time (needing a defined schedule or content to let events flow as they will). An examination of on-site food-service managers, for instance, concluded that this particular group is characterized by extroversion (gathering strength from personal interaction), thinking, and judging (which is the MBTI term for an individual who prefers scheduling and planning). ${ }^{32}$

To relate the MBTI profile to communication behavior in this case, one could conclude that individuals most likely to succeed in a foodservice environment would prefer face-to-face communication over written memos, enjoy group interaction, prefer to be brief and concise, talk in terms of purpose and direction, and (in meetings) focus on the task at hand.

Say, for instance, that you are a food and beverage manager who has read research on customers' tipping habits, and you wish to help your employees increase tips so that they will be less inclined to quit their jobs. You note from the

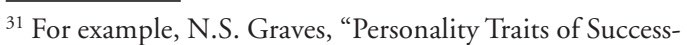
ful Managers as Perceived by Food and Beverage Humanresources Executives and Recruiters," Hospitality Research Journal, Vol. 20, No. 2 (1996), pp. 95-112; and W.L. Gardner and M.J. Martinko, "Using the Myers-Briggs Type Indicator to Study Managers: A Literature Review and Research Agenda," Journal of Management, Vol. 24, No. 1 (1996), pp. 45-83.

${ }^{32}$ J. Brownell, and D. Reynolds, "Personal Style of On-site Food-service Managers," FIU Hospitality Review, Vol. 18, No. 1 (2000), pp. 1-18.
}

study that servers who smile and touch their customers not only are perceived as friendlier, but also receive larger tips. ${ }^{33}$ Your task is to encourage your servers to change their behavior in keeping with those findings. Given the profile described above, it is likely that you would call a meeting of your employees rather than send out a memo. Your session would be short and to the point, with the clear goal of helping servers to understand the principles involved and to implement relevant research findings to improve performance.

\section{Assessing Managers' Communication Competencies}

Identifying the competencies and characteristics associated with managerial effectiveness will enable you to identify those employees who are likely to advance in your organization. This goal leads logically to a related research concern, performance assessment. Before you can make sound decisions about what type of training or developmental activities your employees need, you must identify their current profile and skill levels. Fortunately, a substantial amount of research has focused on how critical communication and leadership skills are assessed and developed.

Assessment centers. One of the most powerful tools for assessing managerial talent is the assessment center. Research has established the validity of assessment-center methods, which apply multiple situational exercises both to evaluate individuals' current job performance and also to determine how well they are likely to handle new or expanded assignments. ${ }^{34}$ Through the assessment-center experience you not only judge how an individual handles his or her current responsibilities, but you can gain reliable insights into how a candidate might perform new tasks

\footnotetext{
${ }^{33}$ M. Lynn, J. Mykal Le, and D. Sherwyn, "Reach Out and Touch Your Customers," Cornell Hotel and Restaurant Administration Quarterly, Vol. 39, No. 1 (February 1998), pp. 137-149.

${ }^{34}$ For example, see: A. Tziner, S. Ronen, and D. Hacohen, "A Four-year Validation Study of an Assessment Center in a Financial Corporation," Journal of Organizational Behavior, Vol. 14, No. 3 (1993), pp. 225-237; and A. Engelbrecht and H. Fischer, "The Managerial-performance Implications of a Developmental Assessment-center Process," Human Relations, Vol. 48, No. 4 (1995), pp. 387-404.
} 
in the future. Assessment centers also have been used to assist in career planning, to develop specific management skills, or to determine an individual's value orientation. ${ }^{35}$

An advantage of the assessment-center approach is that it accommodates individual differences and provides a clear profile of each person's developmental needs regardless of her background, experience, or skill level. The assessment experience itself has been found to improve employee morale and increase motivation by

\section{It is through effective managerial com- munication practices that ideas gener- ated by applied hospitality research are translated into best practices.}

emphasizing the fact that people grow and change over time. ${ }^{36}$ In addition, employees feel valued when they realize that they are being observed and carefully evaluated by senior executives.

The communication-based challenges used in assessment centers can be tailored to a particular company's specific managerial requirements and values. The process of developing an assessment center might unfold in the following manner. First, documents generated by senior managers are collected and examined. Structured interviews are then conducted with key employees, and from this investigation a list of core communication competencies is developed. Participants, often selected by corporate representatives, engage in a series of activities in which they demonstrate their writing, presentation, group-process, and leadership skills. In the course of the assessmentcenter exercises, participants might be asked to write a letter in response to a guest complaint,

\footnotetext{
${ }^{35}$ See: R. Klimoski and M. Breckner, "Why Do Assessment Centers Work? The Puzzle of Assessment-center Validity," Personnel Psychology, Vol. 40, No. 3 (1987), pp. 243-260; and R.G. Jones and M.D. Whitmore, "Evaluating Developmental Assessment Centers as Interventions," Personnel Psychology, Vol. 48, No. 1 (1995), pp. 377-388.

${ }^{36}$ R.A. Cook and J. Herche, "Assessment Centers: An Untapped Resource for Global Sales-force Management," Journal of Personal Selling and Sales Management, Vol. 62, No. 3 (1992), pp. 31-38.
}

make a difficult group decision that calls for value judgments, or deliver a presentation to new employees on safety procedures. This multi-faceted event enables assessors, who often are corporate executives, to judge and provide feedback to assessment participants. ${ }^{37}$

Findings from research on managerial assessment can guide the difficult decisions regarding employee selection and development. Such research helps to identify individuals who can adapt to change, respond to crises, facilitate innovation, develop supportive cultures, or handle other twenty-first-century leadership challenges.

\section{Service Behavior and Guest Satisfaction}

Communication is critical in service encounters. Exchanges between customers and employees affect such things as guests' perceptions of satisfaction, judgments of quality, and long-term loyalty. In short, good service improves your bottom line. ${ }^{38}$ Because of the service encounter's importance, scholars have taken a variety of approaches to examining communication behavior during this interaction. They have used critical incidents, done content analysis, conducted interviews, and surveyed guests, among other methods. Several examples of recent research projects should clarify the expected contributions of studies in this area.

Restaurant guests who reported specific complaints were surveyed and a content analysis of their responses was performed to understand the specific factors most likely to have caused dissatisfaction. ${ }^{39}$ Researchers following this approach should be able to tell the manager of the "Come

${ }^{37}$ F. Berger and J. Brownell, "Leadership: The Loews Assessment Center, Designed to Nurture Potential Managers, Meets with Success," Lodging, Vol. 22, No. 2 (1996), pp. 54-58.

38 M.D. Haring and J. Mattsson, "A Linguistic Approach to Studying the Quality of Face-to-face Communication," Service Industries Journal, Vol. 19, No. 2 (1999), pp. 28-48.

39 See: A. Susskind, "Efficacy and Outcome Expectations Related to Customer Complaints about Service Experiences," Communication Research, Vol. 27, No. 3 (2002), pp. 353-379; and L.J. Harrison-Walker, "E-complaining: A Content Analysis of an Internet-complaint Forum," Journal of Services Marketing, Vol. 15, No. 4 (2001), pp. 397-412. 
Again Restaurant," for instance, that 15 percent of her guests thought that the seats were uncomfortable, 5 percent thought that the coffee was too strong, 60 percent felt that the service was too slow, and another 20 percent were convinced that an odor of garlic pervaded the room. Such information enables managers to address key problems and directly improve the service experience.

Given the inevitability of dissatisfied guests, it may also be useful to know when such customers will choose to confront the service provider with their problem and when they will just walk away. Researchers have identified the factors that influence this decision, providing practitioners with information that will enable them to obtain more guest feedback and better address issues of service recovery. ${ }^{40}$

Along that line, a manager can understand why a customer is disgruntled when the food is bad or when the server is slow or disorganized, but what about when everything seems to have gone well and the guest is still dissatisfied? Ford's studies on the customer-service exchange have distinguished settings where guests expect gracious, personalized service from those where efficiency is valued..$^{41}$ While customers in all situations value service employees for their effective listening and clear explanation $\mathrm{s}^{42}$ and guests generally appreciate efficient service, ${ }^{43}$ there are specific situations where satisfaction is related directly to service providers' ability to adjust their pace and interaction to meet guests' particular needs. ${ }^{44}$ Making an important service distinction

\footnotetext{
${ }^{40}$ A. Susskind, "Efficacy and Outcome Expectations Related to Customer Complaints about Service Experiences," Communication Research, Vol. 27, No. 3 (2002), pp. 353379 .

${ }^{41}$ W.Z. Ford, "Customer Expectations for Interactions with Service Providers: Relationship versus Encounter Orientation and Personalized Service Communication," Journal of Applied Communication Research, Vol. 29, No. 1 (2001), pp. 1-29.

${ }^{42}$ W.Z. Ford, "Communication and Customer Service," Communication Yearbook, Vol. 22 (1999), pp. 341-375.

${ }^{43}$ M. Nikolich and B. Sparks, "The Hospitality Service Encounter: The Role of Communication," Hospitality Research Journal, Vol. 19, No. 2 (1995), pp. 43-56.

${ }^{44}$ W. Samenfink, "A Quantitative Analysis of Certain Interpersonal Skills Required in the Service Encounter," Journal of Hospitality Research, Vol. 17, No. 2 (1994), pp. 3-16.
}

of that type could clear up numerous frustrations and provide your organization with a clear competitive advantage.

\section{Conclusion}

It is through managerial communication practices - what you say and what you do- that you transform the ideas generated by applied hospitality research into best practices for your organization. It is one thing to acquire insights from research findings in various functional areas, and quite another to realize the potential of those ideas by implementing them in the hospitality workplace.

A wide range of industry concerns can be addressed by applying the principles of managerial communication drawn from studies such as those described in this paper. As has been emphasized, communication research takes many forms. Regardless of the specific methods or approach, findings have the potential to improve management activities in all functional areas. It is through ongoing applied research that critical questions can be answered, significant problems addressed, and cutting-edge practices brought to bear to improve individual and organizational performance. Managerial communication is too important to take for granted, and hospitality environments are too dynamic and complex to rely on yesterday's guidelines and strategies.
Judi Brownell, Ph.D., is a professor at the Cornell University School of Hotel Administration (jlb18@ cornell.edu). The author thanks Cornell professors Daphne Jameson and Craig Snow for their valuable comments on earlier versions of this paper.

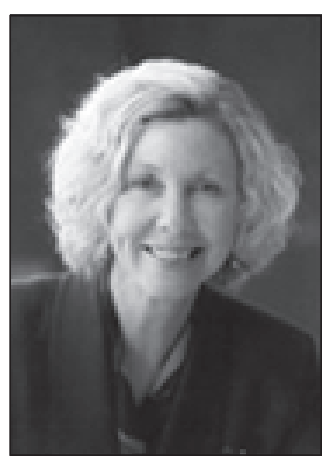

